\title{
A modified minimally invasive osteotomy for hallux valgus enables reduction of malpositioned sesamoid bones
}

\section{Meir Medical Center \\ Nissim Ohana \\ Meir Medical Center \\ Viktor Feldman \\ Meir Medical Center \\ Yaron Brin \\ Meir Medical Center \\ Meir Nyska \\ Tel Aviv University \\ Omer Slevin \\ Meir Medical Center \\ David Segal \\ Meir Medical Center}

Ezequiel Palmanovich ( $\nabla$ ezepalm@gmail.com )

\section{Research Article}

Keywords: hallux valgus, distal metatarsal osteotomy, minimally invasive chevron and akin, metatarsal sesamoid bones

Posted Date: December 2nd, 2020

DOI: https://doi.org/10.21203/rs.3.rs-103511/v1

License: @ (i) This work is licensed under a Creative Commons Attribution 4.0 International License. Read Full License 


\section{Abstract}

Background: Current minimally invasive distal metatarsal osteotomy for hallux valgus (HV) is V-shaped, which prevents correcting the rotational metatarsal head deformity and reduction of sesamoid bones. We aimed to determine the optimal method for sesamoid bone reduction in HV surgery.

Methods: We reviewed the records of 53 patients who underwent HV surgery by a single surgeon from 2017 to 2019 according to one of three techniques: open chevron osteotomy ( $n=19)$, minimally invasive V-shaped osteotomy $(n=18)$ and a modified, straight minimally invasive osteotomy $(n=16)$. Sesamoid position was graded using the Hardy and Clapham method based on standing radiographs.

Results: Postoperative sesamoid position scores were significantly lower (better) following the modified osteotomy than following open chevron osteotomy and V-shaped osteotomy $(1.44 \pm 0.81,3.74 \pm 1.48$ and $4.61 \pm 1.09$, respectively, $P<0.001)$; and the mean change in score was greater $(P<0.001)$.

Conclusion: Modified minimally invasive osteotomy was superior to the two other techniques, in the correction of HV deformity in all planes, including sesamoid reduction.

\section{Introduction}

Hallux valgus (HV) surgery, also known as bunion surgery, is a common procedure that is performed by foot and ankle surgeons.[1][2] The patients present with a painful medial bump, medial deviation of the first ray, and lateral deviation and pronation of the big toe.[3] Over the years, more than 150 open surgery techniques to correct this deformity have been described.[2] The last decade has witnessed a conceptual change regarding bunion surgery[4], and minimally invasive approaches have become very popular outside the USA.[1] The main advantages of these new techniques are lower morbidity and shorter recovery time;[5] however, the reported outcomes have varied.[1,6-9] The minimally invasive chevron and akin (MICA) procedure, which was described primarily by Vernois and Redfern,[9] has become widely used. The main advantage of this procedure is that it is extra-articular, which likely reduces the incidence of postoperative complications.

The success rate of $\mathrm{HV}$ surgeries has been correlated with the preoperative severity of the deformity. $\mathrm{HV}$ angles (HVA) larger than 37 or 40 degrees have been reported to be a risk factor for recurrence.[10][11] However, the HVA represents only one aspect of a three-dimensional deformity. As the first metatarsal bone (MT1) shifts medially, the tendon and ligament insertions change their orientations. As a result, the generated muscle forces abduct and pronate the hallux and rotate the MT1 internally. The MT1 head shifts further medially with respect to the hallux flexors, where the sesamoid bones are embedded. Consequently, the sesamoid bones are repositioned laterally and drift dorsally. Up to 88\% of HV cases present with an internally malrotated hallux on clinical examination.[12] The laterally displaced sesamoid bones can be clearly visualized on a dorsoplantar X-ray radiograph. Thus, in addition to the preoperative HVA, deformity recurrence has also been associated with incomplete reduction of the laterally displaced sesamoid bones.[12] Unreduced sesamoid bones have been associated with joint arthritis, recurrence of 
the deformity and pain while walking.[13,14] Therefore, proper reduction of the sesamoid bones is essential in HV surgery.

As described by Vernois and Redfern, the minimally invasive distal metatarsal osteotomy is V-shaped. This configuration does not enable the surgeon to correct the rotational deformity of the MT1 head. Recently, we developed a modification of the procedure, by which a straight osteotomy, perpendicular to the MT1 shaft, is done instead of the V-shaped cut (Figure 1). This enables de-rotating the MT1 head, and thereby reducing the sesamoid bones into their normal position under the MT1 head. In this study, we compared the positions of the postoperative sesamoid bones following three surgical techniques: open chevron, minimally invasive V-shaped osteotomy, and the modified "straight" minimally invasive osteotomy. We aimed to determine the optimal method for sesamoid bone reduction in HV surgery.

\section{Methods}

We reviewed the records of 53 patients who underwent HV surgery by a single surgeon during the years 2017 to 2019. The patients were operated using one of three surgical techniques. During 2017, an open chevron osteotomy was performed on 170 patients with mild to moderate HV, based on Nyska classification.[15] The last 19 patients who were operated by this method during 2017 constituted "group C" ("C" for chevron). During 2018, a minimally invasive V-shaped osteotomy (MICA) was performed on 18 HV patients, who constituted "group V". In "group M" (for modified), we included 16 HV patients who were operated at the end of 2018 and during 2019 by a modified, "straight" minimally invasive osteotomy (Figures 1,2).

We included patients, both males and females, aged 15-99 years, who had a mature bone structure (closed physis on preoperative X-ray radiographs). They all had available preoperative weightbearing orthogonal foot radiographies. Study exclusion criteria were immature bones, a history of multiple foot surgeries, Charcot foot or other structural foot abnormalities in addition to HV, metatarsus adductus associated with $\mathrm{HV}$, and a recent trauma to the foot. We defined $\mathrm{HV}$ as an inter-metatarsal angle (IMA) greater than 8 degrees. The indication for surgery was pain that was associated with a diagnosed HV and that was not alleviated by non-surgical measures.

Pre- and postoperative standing $\mathrm{X}$-ray radiographs were evaluated for every patient. We used radiographs that were obtained at a mean of $12 \pm 3$ weeks postoperatively. Pre- and postoperative HVA and IMA were measured by a single surgeon (EP) using PACS software (Carestream Vue PACS, Fujifilm Corporation, JAPAN).[15] We used the Hardy and Clapham method[16] to assess the position of the medial sesamoid bone on an anteroposterior radiograph of the foot. Briefly, the position of the medial sesamoid relative to the centerline of the first metatarsal on the dorsoplantar plane was determined. Position I was considered normal. Position IV was defined when the first metatarsal midline crossed the medial sesamoid midline, and a displacement (positions V-VII) was graded according to the medial distance of the sesamoid location (Figure 3). 
The original percutaneous chevron osteotomy was described previously.[9] In the modification presented herein, the osteotomy was performed in a straight line, perpendicular to the metatarsal axis on the sagittal view, as shown in Figure 1. Before fragment fixation, we supinated the big toe, pulling the MT1 head along with it, until the sesamoids were shown by fluoroscopy to return to the normal position under the metatarsal head (Figure 4). Then, the K-wires were inserted into the metatarsal head and were followed by cannulated screw fixation (Figure 5). The postoperative regimen included immediate weight bearing with Flat DARCO shoe (MedSurg ${ }^{\mathrm{TM}}$, Huntingon WV). During the first follow-up visit, at two weeks, dressings were changed and weightbearing X-rays were taken. At 6 weeks, K-wires were removed when necessary; and at twelve weeks, weightbearing X-rays were taken again.

\section{Statistical analysis}

SPSS 25 software (Chicago, IL) was used for the statistical analysis. Descriptive statistics were applied to the data. The Fisher's exact test and the Student's $t$-test were used to compare categorical and continuous variables, respectively. An ANOVA, followed by a post-hoc pairwise analysis when needed, was used to compare the pre- and postoperative IMA, HVA and sesamoid bone position between patients who underwent the three procedures. A paired samples $t$-test was applied to compare the IMA, HVA and sesamoid bone positions, before and after surgery, between patients who underwent the three procedures. An alpha of 0.05 was considered significant.

\section{Results}

The age, sex and radiographic measurements of the study population are presented in Table 1. Statistically significant differences in the demographic variables assessed or in IMA were not observed between the three study groups $(P>0.05)$. The HVA was found to be the narrowest (i.e., a smaller deformity) in group $C$ (open chevron osteotomy) $(P<0.01)$.

Overall, the mean sesamoid bone position score before surgery was $5.04 \pm 1.26$, and did not differ significantly between the three groups $(P=0.16)$. Following surgery, this score was significantly lower in group $M(1.44 \pm 0.81, P<0.001)$ than in groups $C(3.74 \pm 1.48)$ and $V(4.61 \pm 1.09)$. While the sesamoid bone position score improved by $4 \pm 1.37$ points in group $M$, the mean decreases (improvement) were only $0.89 \pm 0.99$ and $0.5 \pm 0.71$ points in groups $C$ and $V$, respectively $(P<0.001)$ (Figure 6$)$. The largest mean decreases (improvement) in IMA and HVA were achieved in group $M(P<0.01$, Table 1$)$.

\section{Discussion}

This study showed that application of a modified, "straight" osteotomy through a minimally invasive approach corrected the IMA and HVA in patients with HV; and, simultaneously, reduced the laterally displaced sesamoid bones into a non-pathological position. The modified osteotomy enabled addressing the three-dimensional configuration of the deformity and correcting its rotational aspect. As a result, more 
effective sesamoid reduction was achieved compared with open chevron osteotomy and with the original V-shaped MICA.

The importance of MT1 rotation during HV surgery has gained attention over the years.[17] Residual postoperative lateral displacement of sesamoids has been shown to be associated with HV recurrence, $[10-12,17]$ walking pain and arthritis.[14] Accordingly, several attempts have been made to correct the rotational element of the $\mathrm{HV}$ deformity and to reduce the sesamoid bones into their natural position. Nyska et al.[18] studied various Ludloff osteotomy angles in an attempt to identify the optimal cut for correction of the pronation. Wagner et al.[17] proposed an osteotomy technique that aimed to address the three-dimensional complexity of the HV deformity by a proximal rotational metatarsal osteotomy (PROMO). Okuda presented a proximal supination osteotomy that would simultaneously correct both the varus and the pronation of the MT1.[19] Although effective, these methods were described as open surgery techniques, thus lacking the benefits of the minimally invasive approach.

The minimally invasive technique that was introduced by Vernois and Redfern[9] is composed of three basic elements: a percutaneous V-shaped distal osteotomy, lateral displacement of the head, and fixation of the new fragment configuration. These steps can be accompanied by a bunion osteo-resection and an akin osteotomy, and are conducted via skin cuts of several millimeters in length. The advantages of a minimally invasive technique are lower morbidity and shorter recovery time, less pain and a better range of motion of the metatarsophalangeal joint. [5] In addition, the minimal skin cuts result in less skin compilations and smaller scars.[20] The V-shaped osteotomy[9] enables correcting both mild and severe deformities, but it restricts the surgeon to correction in a single plane. The de-rotation of the MT1 head and consequent correction in sesamoid position is not possible when the metatarsophalangeal center of rotation shift is insufficient for sesamoid reorientation. The modification that we describe here eliminates the restriction that was formed by the V-shaped osteotomy, and enables correction of the sesamoid bone position by de-rotation of the MT1 head. In the current series of 53 patients, the straight osteotomy was the only technique that yielded a successful sesamoid reduction. This method enabled combining the benefits of a minimally invasive technique with the possibility of correcting the three-dimensional HV configuration. Disadvantages of the technique include the plantar or doxiflexion of the metatarsal head displacement during the translation, since there is no $\mathrm{V}$ shape to avoid the displacement. Particular attention is needed during the fixation, which should be performed under true lateral fluoroscopy.

The V-shaped osteotomy offers two main advantages. First, the V shape creates a larger contact area between the two bone fragments, compared with a straight cut. Moreover, the V-Y is presumed to be a more stable configuration, compared with two flat-shaped bones that could slide over each other. Nevertheless, we feel that these benefits of the original method were outweighed by the ability to manipulate the MT1 head in all planes, which achieved optimal correction. The eventual fixation of the two fragments by two cannulated screws eliminated the shearing and rotational movements between the two fragments. 
This study had several limitations. Its retrospective nature prevented prospective patient randomization and allocation to the three procedure groups. The study design also dictated the use of standing X-ray radiographs for sesamoid evaluation, since this is the imaging modality that is commonly applied for patients with HV at our center. However, standing CT scans could have better demonstrated the exact sesamoid location.[17] Since this was solely a radiographic study, we did not present the clinical outcomes or union rates of our patients. However, the clinical follow-up is of great interest; thus, we are planning a future study in which these data will be presented in detail.

In conclusion, the "straight" osteotomy modification of the MICA procedure enabled reducing the HV deformity in all planes, and was the only method by which we were able to reduce the sesamoid bones into their normal position.

\section{Declarations}

- Ethics approval and consent to participate: all protocols were carried out in accordance with relevant guidelines and regulations, a statement confirming all the methods have been approved by the institutional ethical committee (Meir Medical Center institutional review board). The study was approved by Meir Medical Center institutional review board. A wavier of informed consent was issues by the Meir Medical Center institutional review board due to the retrospective nature of this study.

- Consent for publication: Not applicable.

- Availability of data and material: The datasets used and/or analyzed during the current study are available from the corresponding author on reasonable request

- Competing interests: There are no competing interests to declare.

- Funding: This research did not receive any specific grant from funding agencies in the public, commercial, or not-for-profit sectors.

- Authors' contributions

- EP: Study design, and surgery and preparation of the first draft of the manuscript.

- NO: Critical review of the manuscript and interpretation.

- DS: Statistical analysis

- OS: Statistical analysis

- YB + VF: Data collection and review of the manuscript.

- NM: Study design

- Acknowledgements: We thank Nitzan Konstantin and Cindy Cohen for editorial assistance.

\section{References}

1. De Prado M. Minimally invasive foot surgery: A paradigm shift. Minim. Invasive Surg. Foot Ankle. Springer London; 2011. p. 3-11. 
2. Ferrari J, Higgins JPT, Prior TD. Interventions for treating hallux valgus (abductovalgus) and bunions. Cochrane database Syst. Rev. [Internet]. 2004 [cited 2020 Mar 11];CD000964. Available from: http://www.ncbi.nlm.nih.gov/pubmed/14973960

3. Fraissler L, Konrads C, Hoberg M, Rudert M, Walcher M. Treatment of hallux valgus deformity. EFORT Open Rev. British Editorial Society of Bone and Joint Surgery; 2016;1:295-302.

4. Palmanovich $\mathrm{E}$, Myerson MS. Correction of moderate and severe hallux valgus deformity with a distal metatarsal osteotomy using an intramedullary plate [Internet]. Foot Ankle Clin. W.B. Saunders; 2014 [cited 2020 Mar 11]. p. 191-201. Available from:

http://www.ncbi.nlm.nih.gov/pubmed/24878409

5. Maffulli N, Longo UG, Marinozzi A, Denaro V. Hallux valgus: effectiveness and safety of minimally invasive surgery. A systematic review. Br. Med. Bull. [Internet]. 2011 [cited 2020 Mar 11];97:149-67. Available from: http://www.ncbi.nlm.nih.gov/pubmed/20710024

6. Giannini S, Bevoni R, Vannini F, Cadossi M. Hallux Valgus Surgery: The Minimally Invasive Bunion Correction. Minim. Invasive Surg. Orthop. Springer New York; 2010. p. 463-71.

7. Magnan B, Pezzè L, Rossi N, Bartolozzi P. Percutaneous distal metatarsal osteotomy for correction of hallux valgus. J. Bone Jt. Surg. - Ser. A [Internet]. 2005 [cited 2020 Mar 11];87:1191-9. Available from: http://www.ncbi.nlm.nih.gov/pubmed/15930526

8. Malagelada F, Sahirad C, Dalmau-Pastor M, Vega J, Bhumbra R, Manzanares-Céspedes MC, et al. Minimally invasive surgery for hallux valgus: a systematic review of current surgical techniques. [Internet]. Int. Orthop. Springer Verlag; 2019 [cited 2020 Mar 11]. p. 625-37. Available from: http://www.ncbi.nlm.nih.gov/pubmed/30218181

9. Vernois J, Redfern DJ. Percutaneous Surgery for Severe Hallux Valgus [Internet]. Foot Ankle Clin. W.B. Saunders; 2016 [cited 2020 Mar 11]. p. 479-93. Available from: http://www.ncbi.nlm.nih.gov/pubmed/27524702

10. Deenik AR, De Visser E, Louwerens JWK, Malefijt MDW, Draijer FF, De Bie RA. Hallux valgus angle as main predictor for correction of hallux valgus. BMC Musculoskelet. Disord. 2008;9.

11. Okuda R, Kinoshita M, Yasuda T, Jotoku T, Shima H, Takamura M. Hallux valgus angle as a predictor of recurrence following proximal metatarsal osteotomy. J. Orthop. Sci. [Internet]. Springer Tokyo; 2011 [cited 2020 Mar 11];16:760-4. Available from:

http://www.ncbi.nlm.nih.gov/pubmed/21818604

12. Okuda R, Kinoshita M, Yasuda T, Jotoku T, Kitano N, Shima H. Postoperative incomplete reduction of the sesamoids as a risk factor for recurrence of hallux valgus. J. Bone Jt. Surg. - Ser. A [Internet]. Journal of Bone and Joint Surgery Inc.; 2009 [cited 2020 Mar 11];91:1637-45. Available from: http://www.ncbi.nlm.nih.gov/pubmed/19571086

13. Katsui R, Samoto N, Taniguchi A, Akahane M, Isomoto S, Sugimoto K, et al. Relationship between Displacement and Degenerative Changes of the Sesamoids in Hallux Valgus. Foot Ankle Int. [Internet]. SAGE Publications Inc.; 2016 [cited 2020 Mar 11];37:1303-9. Available from: http://www.ncbi.nlm.nih.gov/pubmed/27530982 
14. Suzuki J, Tanaka Y, Takaoka T, Kadono K, Takakura Y. Axial radiographic evaluation in hallux valgus: evaluation of the transverse arch in the forefoot. J. Orthop. Sci. [Internet]. Springer Japan; 2004 [cited 2020 Mar 11];9:446-51. Available from: http://www.ncbi.nlm.nih.gov/pubmed/15449119

15. Nyska M. Principles of first metatarsal osteotomies. Foot Ankle Clin. [Internet]. 2001 [cited 2020 Mar 11];6:399-408. Available from: http://www.ncbi.nlm.nih.gov/pubmed/11692489

16. Hardy RH, Clapham JCR. OBSERVATIONS ON HALLUX VALGUS. J. Bone Joint Surg. Br. [Internet]. 1951 [cited 2020 Mar 11];33-B:376-91. Available from:

http://online.boneandjoint.org.uk/doi/10.1302/0301-620X.33B3.376

17. Wagner P, Ortiz C, Wagner E. Rotational Osteotomy for Hallux Valgus. A New Technique for Primary and Revision Cases. Tech. foot ankle Surg. [Internet]. Lippincott Williams and Wilkins; 2017 [cited 2020 Mar 11];16:3-10. Available from: http://www.ncbi.nlm.nih.gov/pubmed/28286430

18. Nyska M, Trnka H-J, Parks BG, Myerson MS. The Ludloff metatarsal osteotomy: guidelines for optimal correction based on a geometric analysis conducted on a sawbone model. Foot ankle Int. [Internet]. 2003 [cited 2020 Mar 11];24:34-9. Available from:

http://www.ncbi.nlm.nih.gov/pubmed/12540079

19. Okuda R. Proximal Supination Osteotomy of the First Metatarsal for Hallux Valgus [Internet]. Foot Ankle Clin. W.B. Saunders; 2018 [cited 2020 Mar 11]. p. 257-69. Available from: http://www.ncbi.nlm.nih.gov/pubmed/29729800

20. Frigg A, Zaugg S, Maquieira G, Pellegrino A. Stiffness and Range of Motion After Minimally Invasive Chevron-Akin and Open Scarf-Akin Procedures. Foot Ankle Int. [Internet]. SAGE Publications Inc.; 2019 [cited 2020 Mar 11];40:515-25. Available from:

http://www.ncbi.nlm.nih.gov/pubmed/30688526

\section{Tables}

Table 1. Demographic and radiographic characteristics of patients who were operated for hallux valgus, according to three methods $(n=53)$. 


\begin{tabular}{|c|c|c|c|c|c|}
\hline & $\begin{array}{l}\text { Open chevron } \\
\text { osteotomy } \\
(n=19)\end{array}$ & $\begin{array}{l}\text { V-shaped } \\
\text { MICA }(n=18)\end{array}$ & $\begin{array}{l}\text { Modification } \\
\text { osteotomy } \\
(n=16)\end{array}$ & $\begin{array}{l}\text { Total } \\
(n=53)\end{array}$ & $\begin{array}{l}\text { Significance } \\
(P \text {-value })\end{array}$ \\
\hline $\begin{array}{l}\text { Age (mean } \pm S D, \\
\text { range) years }\end{array}$ & $\begin{array}{l}61.11 \pm 10.61 \\
37-74\end{array}$ & $\begin{array}{l}56.72 \pm 15.04 \\
17-78\end{array}$ & $\begin{array}{l}54.31 \pm 20.66 \\
15-72\end{array}$ & $\begin{array}{l}57.66 \pm 15.6 \\
15-78\end{array}$ & 0.4 \\
\hline Sex (male; $n, \%)$ & $3(15.8 \%)$ & $1(5.6 \%)$ & $3(18.8 \%)$ & $7(13.2 \%)$ & 0.6 \\
\hline $\begin{array}{l}\text { Side (right; } n \\
\%)\end{array}$ & $9(47.4 \% 0$ & $12(66.7 \%)$ & 6 (37.5\%) & 27 (50.9\%) & 0.24 \\
\hline \multicolumn{6}{|l|}{ Preoperative } \\
\hline $\begin{array}{l}\text { Sesamoid } \\
\text { position* }\end{array}$ & $4.63 \pm 1.26$ & $5.11 \pm 0.96$ & $5.44 \pm 1.46$ & $5.04 \pm 1.26$ & 0.16 \\
\hline IMA & $13.63 \pm 2.79$ & $13.67 \pm 2.97$ & $13.63 \pm 2.03$ & $13.64 \pm 2.6$ & 1 \\
\hline HVA & $30.58 \pm 7.01$ & $35.67 \pm 8.04$ & $38.75 \pm 7.02$ & $34.77 \pm 8$ & $<0.01$ \\
\hline \multicolumn{6}{|l|}{ Postoperative } \\
\hline $\begin{array}{l}\text { Sesamoid } \\
\text { position }\end{array}$ & $3.74 \pm 1.48$ & $4.61 \pm 1.09$ & $1.44 \pm 0.81$ & $3.34 \pm 1.75$ & $<0.001$ \\
\hline IMA & $6.53 \pm 2.86$ & $5.06 \pm 2.6$ & $3.25 \pm 2.35$ & $5.04 \pm 2.9$ & $<0.01$ \\
\hline$H V A$ & $18.79 \pm 7.44$ & $20.17 \pm 6.61$ & $15.19 \pm 6.4$ & $18.17 \pm 7.04$ & 0.1 \\
\hline \multicolumn{6}{|l|}{$\begin{array}{l}\text { Difference } \\
\text { (mean } \pm S D, P \text { - } \\
\text { value) }\end{array}$} \\
\hline $\begin{array}{l}\text { Sesamoid } \\
\text { position }\end{array}$ & $\begin{array}{l}0.89 \pm 0.99 \\
0.001\end{array}$ & $\begin{array}{l}0.5 \pm 0.71 \\
0.08\end{array}$ & $4 \pm 1.37,<0.001$ & $1.7 \pm 1.85$ & $<0.001$ \\
\hline$I M A$ & $\begin{array}{l}7.11 \pm 2.77 \\
<0.001\end{array}$ & $\begin{array}{l}8.61 \pm 2.87 \\
<0.001\end{array}$ & $\begin{array}{l}10.38 \pm 3.69 \\
<0.001\end{array}$ & $8.6 \pm 3.3$ & $<0.001$ \\
\hline HVA & $\begin{array}{l}11.79 \pm 9.66 \\
<0.001\end{array}$ & $\begin{array}{l}15.5 \pm 8.51 \\
<0.001\end{array}$ & $\begin{array}{l}23.65 \pm 7.13 \\
<0.001\end{array}$ & $16.6 \pm 9.7$ & $<0.001$ \\
\hline
\end{tabular}

* The sesamoid bone position is scored on a 7-point scale, as originally presented by Hardy and Clapham. ${ }^{7}$

Abbreviations: MICA, minimally invasive chevron and akin; SD, standard deviation; IMA, inter-metatarsal angle; HVA: hallux valgus angle.

\section{Figures}




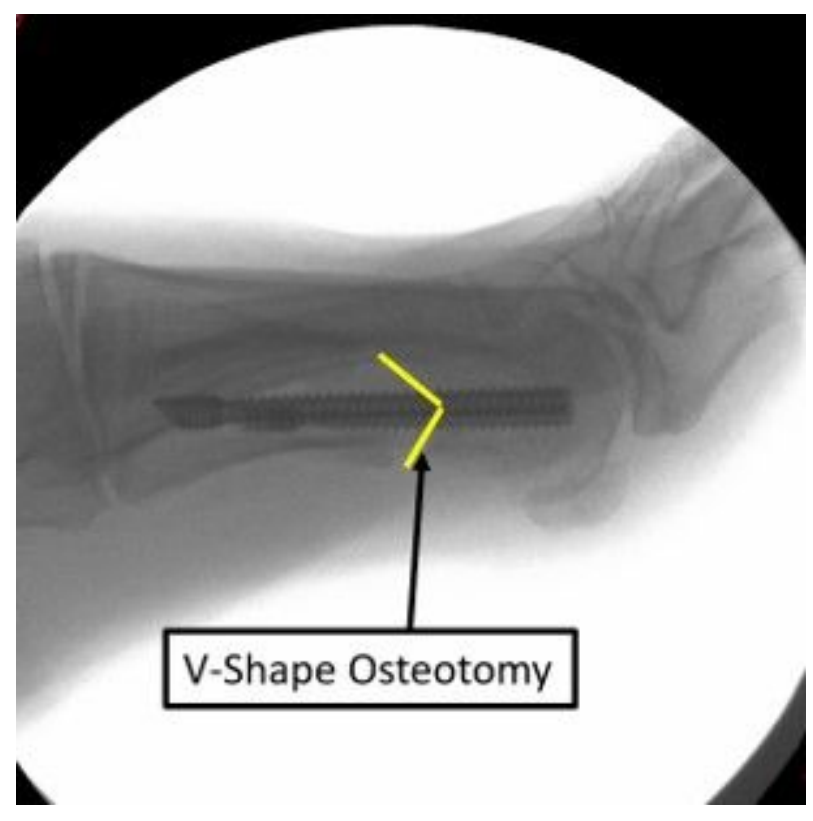

Figure 1

Minimally invasive osteotomy for hallux valgus. V-shaped osteotomy

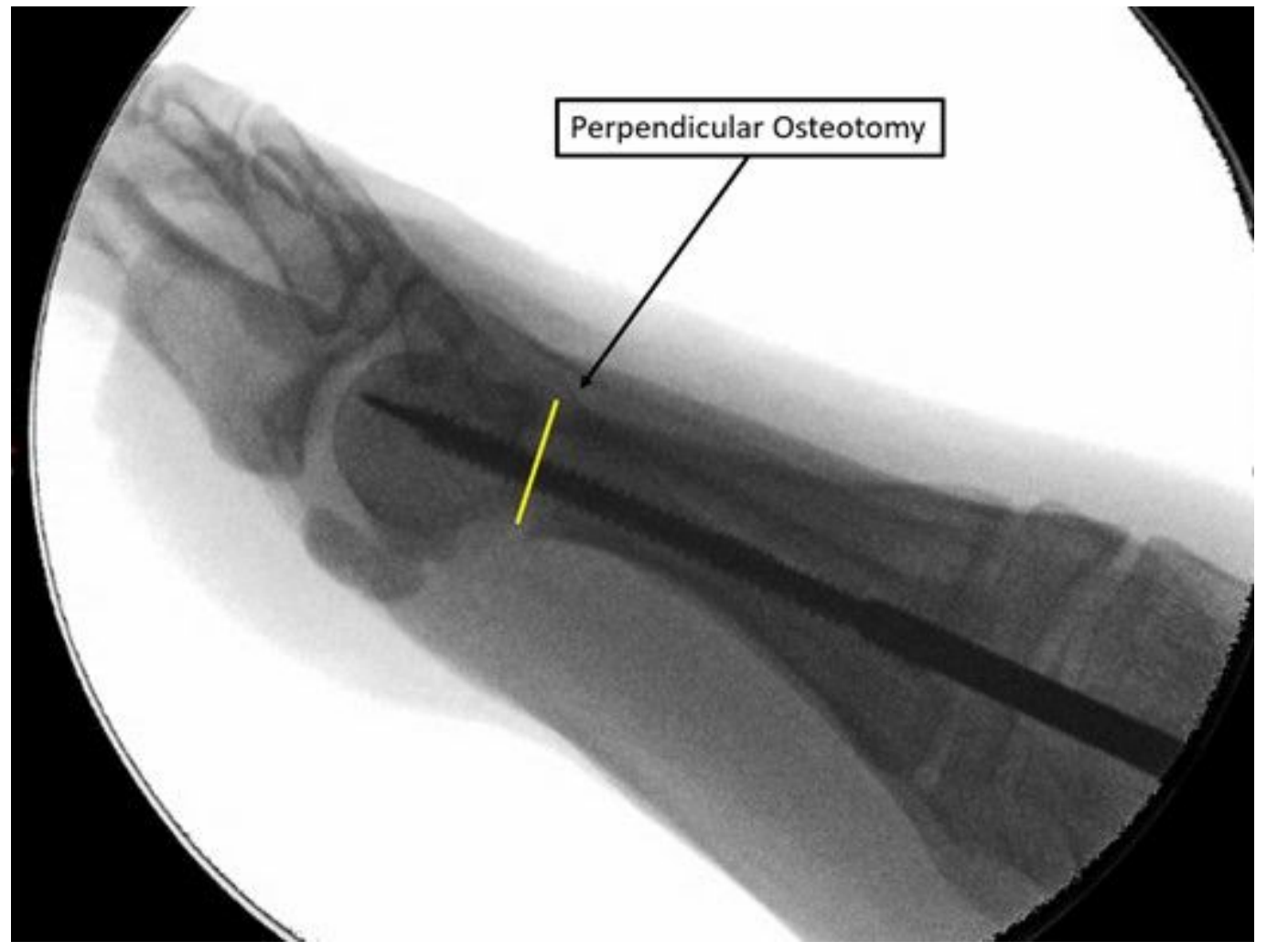

Figure 2

Minimally invasive osteotomy for hallux valgus. Modified straight osteotomy. 


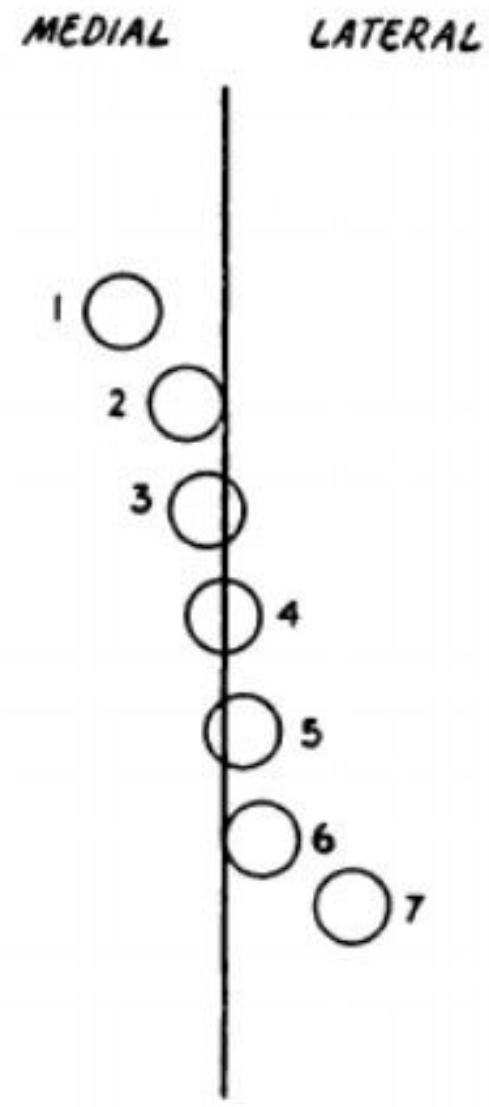

\section{Figure 3}

Drawing of the sesamoid bone position score introduced by Hardy and Clapham.16 The position of the medial sesamoid bone is determined in relation to the first metatarsal bone midline.

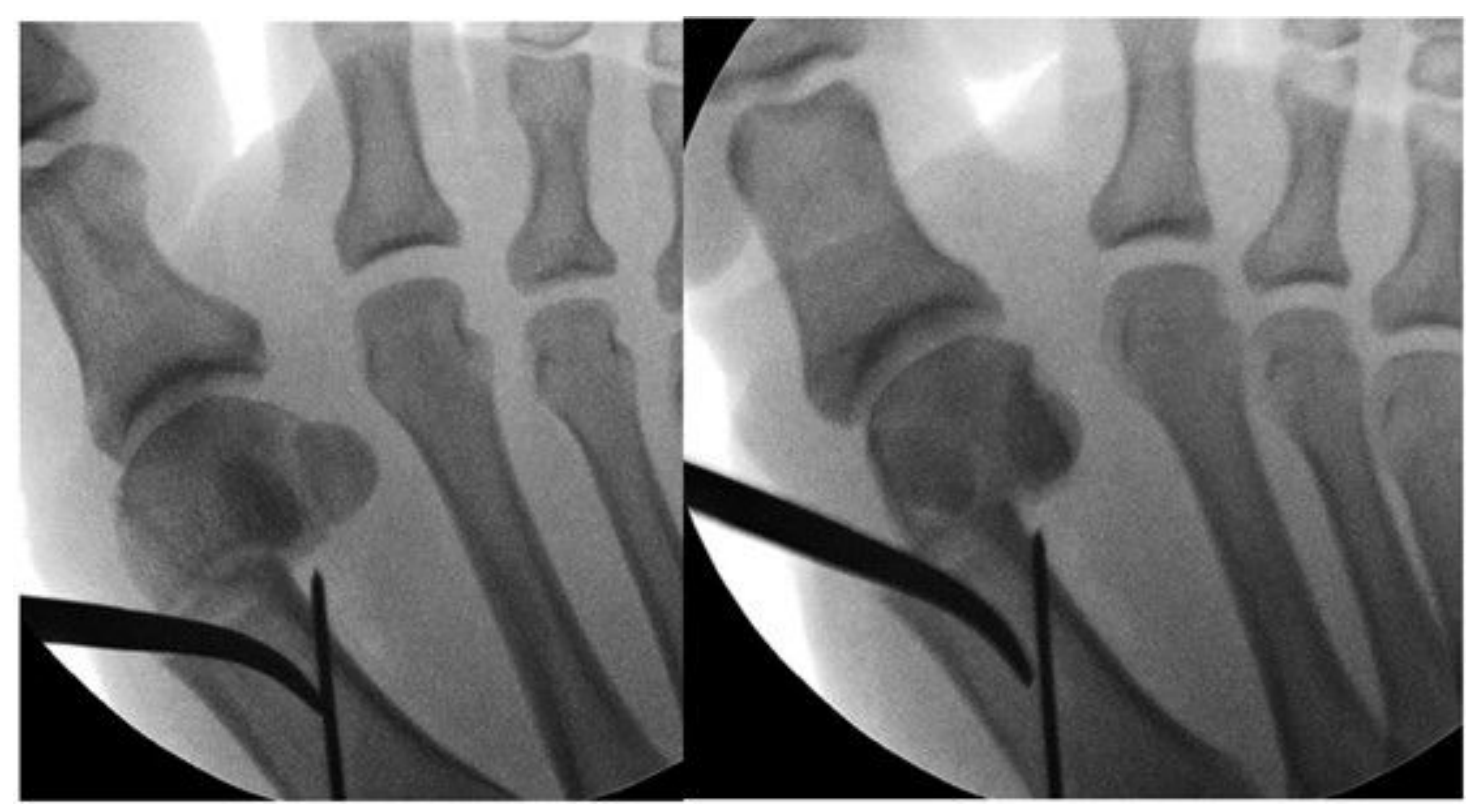

Figure 4 
Intraoperative rotation of the metatarsal head on fluoroscopy. A. A pronated metatarsal head with subluxed sesamoid bones. B. A de-rotated (supinated) metatarsal head with reduced sesamoid bones.

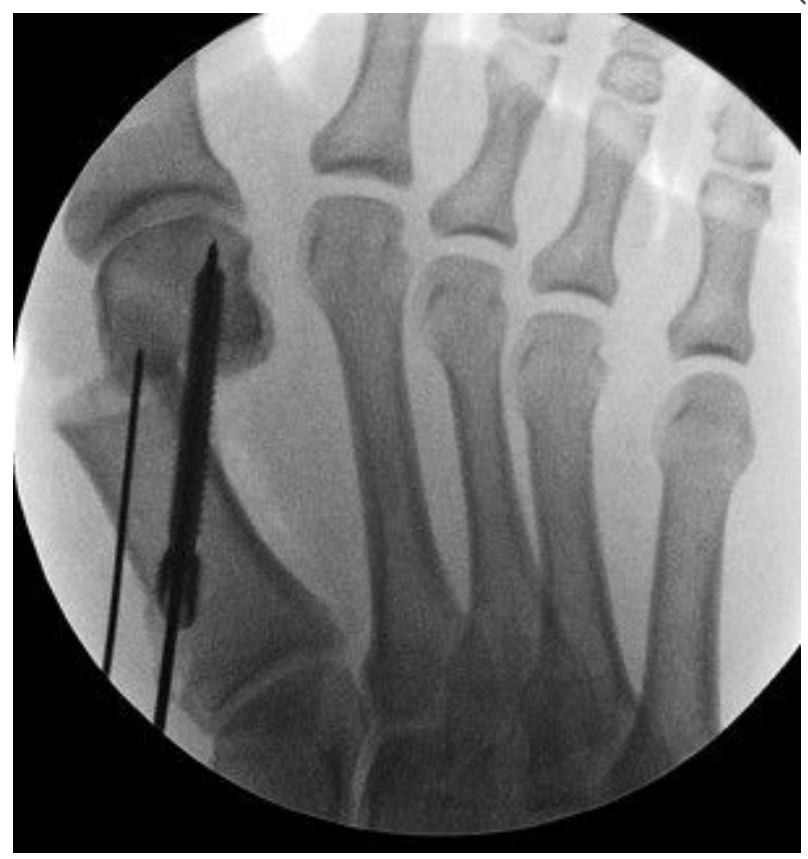

\section{Figure 5}

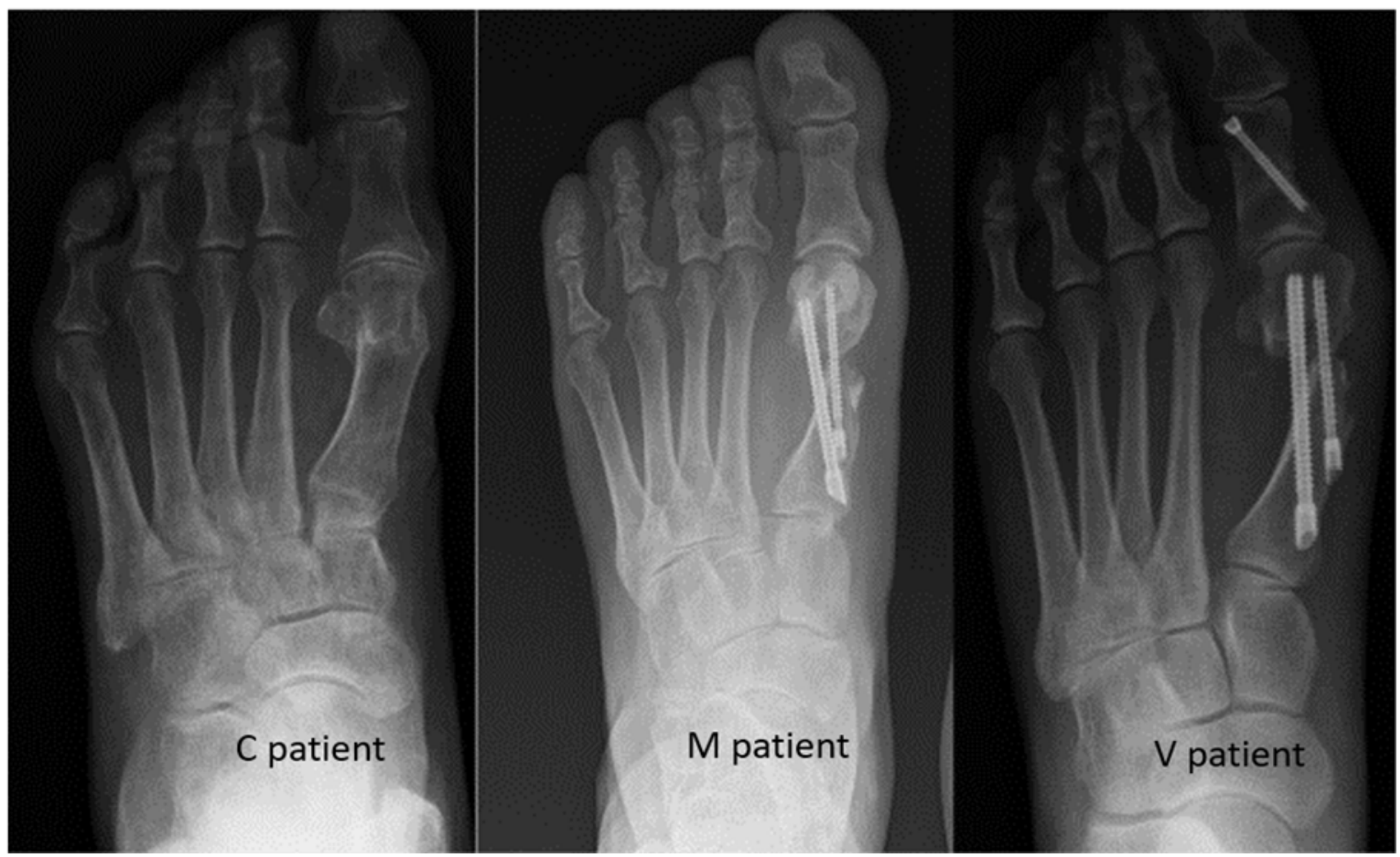

Figure 6 
Postoperative X-ray radiographs following hallux valgus surgeries. A. Open chevron osteotomy. B. Minimally invasive modified straight osteotomy. C. Minimally invasive modified straight osteotomy with akin procedure. 